\title{
Awareness and Determinants of Telemedicine Adoption at Ga West District of Ghana
}

\author{
Linda Hyde-Quartey \\ School of Management, Jiangsu University \\ Zhenjiang 212013, P.R. China \\ Chen Hao \\ School of Management, Jiangsu University \\ Zhenjiang 212013, P.R. China \\ Priscilla Adomako-Gyasi \\ School of Management, Jiangsu University \\ Zhenjiang 212013, P.R. China \\ Ahotovi Thomas Ahoto \\ School of Management, Jiangsu University \\ Zhenjiang 212013, P.R. China
}

Received: October27, 2020

doi:10.5296/ijmis.v6i1.17886
Accepted: April 22, 2021

Published: May 15, 2021

URL: https://doi.org/10.5296/ijmis.v6i1.17886

\begin{abstract}
The need to have regular visitation to the hospital or be in the physical presence of healthcare professionals for treatment is gradually reducing. By the advancement in technology, an individual can receive treatment from the doctor or other health information through telemedicine. Telemedicine has gain ground in developed nations with many developing countries trying the adoption in practice. This study is a quantitative study that uses the question to collect data from respondents within the Ga West District in the Greater Accra Region of Ghana. A total of 226 respondents were involved in the study. The study aimed to
\end{abstract}




\section{Macrothink}

International Journal of Management Innovation Systems

ISSN 1943-1384

measure the level of awareness about telemedicine among people living in the district, factors that influence the adoption of telemedicine and barriers preventing adoption. The findings indicated that there was a high level of awareness about telemedicine among the respondents with most of them knowing what telemedicine is. Adoption was also influenced by a reduction in treatment when use telemedicine, prevention of overcrowding at hospitals and the taken away of time wasted at the hospital. It was also determined that poor internet connectivity and high cost of data were the significant barriers impeding the adoption of telemedicine among the district dwellers.

Keywords: Telemedicine in Ghana, Ga-West, Adoption of Telemedicine, Technology in healthcare, Barriers to Telemedicine 


\section{Mll Macrothink}

\section{Introduction}

Development in technology has aided all aspects of human activities, it has a speed of delivery services has improved, reduce expenditure on service delivery, ease ways of doing things, and people to work away from physical offices (Wang et al., 2018). Health delivery has received its fair share of technological development as quality in treating and caring for patients has been upgraded than never before (Hamilton et al., 2019). Today's patients are in constant demand for improved services, yet they have less time for attending hospitals or having physical interactions with healthcare workers (Saleem et al., 2020).

The World Health Organization (WHO) defines e-health as the cost-effective use of Information Communication and Technology (ICT) in support of health services, health surveillance, education, knowledge and research with telemedicine being a significant component (Baudier, Kondrateva, \& Ammi, 2020). Telemedicine referred to the offering of treatment to patients without the physical presence of both parties (the healthcare worker and the patient) (Roncero et al., 2020). Telemedicine has gain ground, especially in developing countries and is being used to deliver health services in both simple and sometimes complex situations (Loeb et al., 2020). The robust technology and fast internet availability have created an enabling environment for this to thrive, but the same cannot be said about developing countries (Wang et al., 2019).

Telemedicine is less heard of in Africa, with countries in sub-Saharan Africa making marginal or no use of the technology. The adoption of telemedicine in Africa comes with numerous challenges as countries on the continent have a high illiteracy rate, less internet connectivity, and other technological gadgets needed for successful adoption and usage of this medical breakthrough (Strohl et al., n. d.). Telemedicine comes in three forms, namely Store-And-Forward, Remote Monitoring and Real-Time Interactive Services (Appiah et al., 2020). Though all these forms of telemedicine can help in uplifting health delivery in Africa, the lack of an enabling environment is making such benefits to elude the population (Khosla, 2020).

Telemedicine seemed to be gaining ground in some communities in Ghana as some private institutions are making an effort to make the public catch up with the technology. To achieve public adoption of telemedicine both the public and the private sector must work towards the establishment of a secure internet connection (broadband), video platform and technological supports services which are components on which telemedicine drives (González-martín et al., 2019).

\section{The Concept of Telemedicine}

Telemedicine is the use of technology (computers, video, phone, messaging) by a medical professional to diagnose and treat patients in a remote location (Hamilton et al., 2019). It is very difficult to state when the term telemedicine emerged, writers have acknowledges that telemedicine could have been necessitated by the distance between health professionals and patients (Waschkau et al., 2020). Though at the time telemedicine could have been practiced without it been termed telemedicine. Rashid et al. (2009) in their book History of Telemedicine: 


\section{Macrothink}

International Journal of Management Innovation Systems

ISSN 1943-1384

Evolution, Context, and Transformation traced the origin of modern telemedicine applications in Europe to a Dutch physician, Willem Einthoven, who had been by long-distance transfer of electrocardiograms in 1905. The researchers mentioned the significant contributions of radio consultations from medical centers in Norway, Italy, and France in the 1920s, 1930s, and 1940s for patients aboard ships at sea and on remote islands.

Telemedicine has again ground in Europe and other developed and developing countries. In the year 2009, the World Health Organization's report on the second global survey on eHealth 2009, identified Telemedicine as an opportunity and developments for member states (Y. Wang et al., 2018). The numerous opportunities presented by telemedicine also come with challenges that serve as barriers to its adaption, especially in less developed countries. Sub-Saharan African countries are faced with many challenges that are impeding the adaption of what the W.H.O regarded as an opportunity (Han et al., 2019). Lack of internet connectivity, plural linguistic system, high levels of illiteracy, unavailability of qualified health professionals is just a few barriers reducing the gains of telemedicine in Africa. Ghana equally has challenges similar to any other African countries and for the concept of telemedicine to make maximum impacts the above challenges must be fixed or reduced (Roncero et al., 2020). The concept of telemedicine can be a game-changer in developing nations' health systems if properly implemented by health authorities and adopted by the public.

\section{Conceptual Framework}

The conceptual framework is based on the Technology Adoption Model which outlines various processes in the uptake of emerging technology in health (Fletcher et al., 2020). The framework is in five sections starting from external variables which are made up of variable that influences technology adoption. These variables serve as a catalyst that speeds the adoption processes or serves as barriers that impede adoption (Hamilton et al., 2019). The next item is the conceptual framework is perceived usefulness which explains public thought about how useful technological intervention is to them. When they find it useful they are quick to adopt, the public will equally pay less attention to technological interventions when they are perceived as not being useful (Cunha et al., 2018).

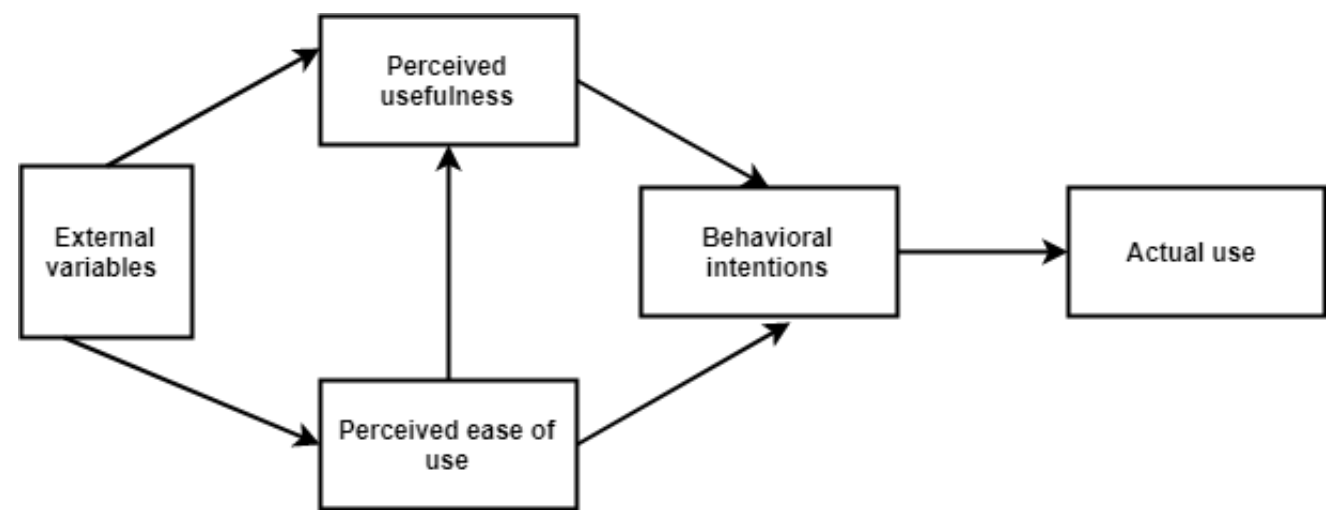

Source: Adopted From Technology Acceptance Model, Davis et al. (1992).

Perceived ease of use indicate how the public finds the technology to be user friendly, external 
variable influences perceived ease of use and perceived usefulness of technology leading to behavioral intentions which may result in the actual use of technology (Arendt, 2016)

\section{Methodology}

The study is a cross-sectional study conducted in selected communities in the Ga east district of the Greater Accra region of Ghana. The quantitative technique was used in data collection by adopting questionnaires that were relevant to the objectives of the study and revised it to fall in line with the research objective. Total of 300 questionnaires was distributed to the participant within the selected communities in Ga east district. The respondents were selected based on their age, sex, education, occupation, number of times they visit the hospital in a year and their accessibility to mobile phones and internet connectivity.

\subsection{Research Setting}

The target population for the study was selected from communities in the Ga West Municipality. The municipality has a population of 270,989 people, it is one of the ten districts in the Greater Accra region. It caved out the existing districts in February 2008 (Blankson et al., 2020). It shares a boundary with the Eastern region and falls within Latitude 50, 48 north, 50, 39 North and Longitude 0,12 West and 0,22 West. The municipality has a municipal hospital, health centers, educational and religious facilities. Other social amenities available are electricity, running water and vehicle terminals. The common health challenges there are malaria, water-borne diseases, noncommunicable diseases and other infectious diseases.

The residents are mainly civil servants, artisans, farmers and fishermen who apply their trade in River Densu. The community was selected for the study because it has a mix of rural and urban outlook. The municipality is cosmopolitan in nature harboring persons from most ethnic groups in Ghana though the majority are from predominately Ga tribe (Gyapong, 2020). The communities in the municipality has internet connectivity and with more than $92 \%$ of the respondents having access to mobile phone.

\subsection{Data Collection and Analysis}

Questionnaires were adopted from previous study and revised to suit the study objectives, these questionnaires were pretested at Nugua a suburb of Accra and further corrections were made to make them fit for purpose. Respondents were selected based on the following criteria; he or she must dwell within the Ga West municipality for the last three years, must be above the ages of 18 years, have a functioning mobile and must be to the hospital in the past three years. The research assistant gave the questionnaires to the participants and wait for them to fill it in their presence (face to face techniques). The research assistants aided the respondent who has difficulty in reading and understanding of the questions.

The research assistants obtain written and verbal informed consent from the respondents and informed them of the right to ignore questions or opt-out at any stage of the process. A total of 296 questionnaires was returned, from which 15 were taken out for incomplete and unclear responses. The rest 281 were used for the analysis using SPSS 20.1. Descriptive Statistics, Pairwise Correlation and Logistic Regression Models were used to show the relationship 


\section{Macrothink \\ International Journal of Management Innovation Systems \\ ISSN 1943-1384 2021, Vol. 6, No. 1}

between the variables and provide answers to the research questions.

\section{Results}

\subsection{Demographic Variables of Respondents}

A total of 226 respondents questionnaires was analyzed of which the majority of (39.3\%) were aged from 26 to 35 years, more than half were educated from senior high to tertiary level, with $62.4 \%$ being female. Most of the respondents (47.0\%) were single with the rest married, cohabiting or divorced. A majority of them (43.4\%) were self-employed, and less than $15 \%$ regarded themselves as unemployed, with less than $15 \%$ also living with chronic conditions. More than $97.8 \%$ owned mobile phones a piece of vital equipment for telemedicine, only $20.4 \%$ has regular access to internet services with the rest having no access or intermittent access to internet services.

Table 1. Demographic Variables of Respondents

$\mathrm{N}=226$

\begin{tabular}{lll}
\hline Variables & Percentages & Frequency (\%) \\
\hline Age & & \\
$18-25$ & 53 & 23.5 \\
$26-35$ & 88 & 39.3 \\
$36-45$ & 41 & 18.1 \\
$46-55$ & 29 & 9.8 \\
Above 55 & 15 & 5.6 \\
\hline Sex & & \\
Female & 141 & 62.4 \\
Male & 85 & 37.2 \\
\hline Education Background & & \\
No formal education & 13 & 5.8 \\
Basic education & 56 & 24.8 \\
Junior high school & 84 & 37.2 \\
Senior high school & 61 & 27.1 \\
Tertiary education & 12 & 5.3 \\
\hline Marital Status & & \\
Single & 106 & 47.0 \\
Cohabitation & 45 & 20.1 \\
Married & 59 & 26.1 \\
Divorced & 16 & 6.0 \\
\hline Occupation & & \\
Unemployed & 28 & 12.4 \\
Self-employed & 98 & 43.4 \\
Civil servant & 43 & 19.0 \\
Company worker & 67 & 29.6 \\
\hline
\end{tabular}


Do you have a chronic condition that warrants periodical medical care

No

Will you accept treatment through Telemedicine

Yes

Do you have access to internet services

Not always

155

Always

Not at all 46
20.4

11.0

\subsection{Awareness about Telemedicine among People Living in Ga East District}

From the table below, more than half of the respondents have had some engagement with healthcare workers on the phone, three-quarters of the respondents have sought health in the hospitals or accompanied relative to seek health in the last three years. $46.5 \%$ of the respondents have received treatment from doctors or nurses without being at their care centers, while $89.3 \%$ of them agreed to have heard of telemedicine.

Half of the respondents first head of telemedicine from the media with the rest hearing it from friends, family or health workers. Mobile phone was mentioned as a vital tool for the adoption of telemedicine by $71 \%$ of the respondents, and $73.1 \%$ also claimed their first experience with telemedicine was delivered through voice call. The majority of the respondents $(63.0 \%)$ have received treatment using telemedicine about one or two times in the past three years.

Table 2.Awareness about Telemedicine among People Living in Ga East District $\quad \mathrm{N}=226$

\begin{tabular}{lll}
\hline Variables & Frequency & $\begin{array}{l}\text { Percentages } \\
(\%)\end{array}$ \\
\hline Have you had an engagement with health workers through the phone & & \\
Yes & 172 & 76.1 \\
No & 34 & 15.0 \\
I can't remember & 20 & 9.0 \\
\hline When was the last time you sick treatment at the hospital or help & & \\
someone to seek treatment & 58 & 22.0 \\
Less than 1 year & 89 & 39.4 \\
In the past 2 years & 33 & 12.4 \\
In the past 3 years & 46 & 20.4 \\
I cannot remember & \\
\hline Have you received treatment from doctor or nurses without you being & 105 & 46.5 \\
present at their workplace & 43 & 19.0 \\
Yes & 78 & 34.5 \\
No & & \\
Cannot remember & & \\
\hline
\end{tabular}


Have you heard of telemedicine

Yes

Where did you first hear of it

Television

Radio

From health worker

From a friend

From family member

What items are needed for telemedicine usage in your area

Mobile phones

Internet

Radio

Computer

How was the communication about treatment delivered to you

Voice calls

Messages

Images

Video calls

How many time have you receive treatment using telemedicine in the

past three years

One to two times

Less than five times

Cannot count

Never
201

25

89.3

11.0

36.5

14.2

32

14.2

25

11.0

15.2

33

6.6

16

7.1

73.0

14.1

32

4.1

20

9.0

142

63.0

21

9.3

11

5.1

52

\subsection{Factors Influencing the Adoption of Telemedicine in the Ga West District and Barriers to} Adoption

More than $80 \%$ of respondents agreed or strongly agreed that one of the factors influencing their adoption of telemedicine is that they do not need to travel to the hospital before seeking treatment. Again telemedicine adoption is also influenced by its ability to help reduce time wasted in the hospital; this was agreed or strongly agreed by $42.0 \%$ and $39.5 \%$ respectively. Telemedicine helps in cutting down the cost of treatment was agreed by less than half of the respondents. Prevention of overcrowding at the hospital was recognized as a factor enabling the acceptance of telemedicine by more than $70 \%$ of the respondent. At the same time, $33.6 \%$ strongly agreed that it enhances communication between healthcare workers and patients. Finally, more than $70 \%$ of the respondents agreed or strongly agreed that telemedicine would help to prevent them from contracting infections from the hospital. 


\section{Macrothink}

International Journal of Management Innovation Systems

ISSN 1943-1384 2021, Vol. 6, No. 1

Table 3. Factors Influencing Adoption of Telemedicine in the Ga West District and Barriers to Adoption: $\mathrm{N}=226$

\begin{tabular}{|c|c|c|}
\hline Variable & Frequency & Percentages $(\%)$ \\
\hline \multicolumn{3}{|c|}{ Prevention of traveling to the hospital always } \\
\hline Strongly Disagree & 9 & 4.1 \\
\hline Disagree & 11 & 5.1 \\
\hline Neither Disagree or Agree & 22 & 10.0 \\
\hline Agree & 98 & 43.2 \\
\hline Strongly Agree. & 86 & 38.0 \\
\hline \multicolumn{3}{|c|}{ Reduce time wasted at the hospital } \\
\hline Disagree & 12 & 5.3 \\
\hline Moderately Disagree & 8 & 3.5 \\
\hline Neither Disagree or Agree & 21 & 9.4 \\
\hline Agree & 95 & 42.0 \\
\hline Strongly Agree. & 89 & 39.5 \\
\hline \multicolumn{3}{|c|}{ Cut down the cost of treatment } \\
\hline Disagree & 13 & 6.1 \\
\hline Moderately Disagree & 11 & 5.1 \\
\hline Neither Disagree or Agree & 23 & 10.2 \\
\hline Agree & 92 & 41.0 \\
\hline Strongly Agree. & 86 & 38.1 \\
\hline \multicolumn{3}{|c|}{ Prevent overcrowding at the hospital } \\
\hline Disagree & 7 & 3.1 \\
\hline Moderately Disagree & 12 & 5.3 \\
\hline Neither Disagree or Agree & 23 & 10.2 \\
\hline Agree & 98 & 43.4 \\
\hline Strongly Agree. & 87 & 38.1 \\
\hline \multicolumn{3}{|c|}{ Improve one on communication with healthcare staff } \\
\hline Disagree & 22 & 9.7 \\
\hline Moderately Disagree & 17 & 8.0 \\
\hline Neither Disagree or Agree & 28 & 12.4 \\
\hline Agree & 81 & 36.0 \\
\hline Strongly Agree. & 75 & 33.2 \\
\hline \multicolumn{3}{|c|}{ Free from the fear of contracting infections of the hospital } \\
\hline Disagree & 6 & 3.4 \\
\hline Moderately Disagree & 9 & 4.5 \\
\hline Neither Disagree or Agree & 25 & 11.1 \\
\hline Agree & 93 & 41.5 \\
\hline Strongly Agree. & 89 & 39.4 \\
\hline \multicolumn{3}{|c|}{ Call nurses at times of difficulties without going to hospital } \\
\hline Disagree & 23 & 10.2 \\
\hline Moderately Disagree & 14 & 6.2 \\
\hline Neither Disagree or Agree & 28 & 12.4 \\
\hline Agree & 82 & 36.3 \\
\hline Strongly Agree. & 78 & 34.5 \\
\hline
\end{tabular}




\subsection{Barriers to the Adoption of Telemedicine in the Ga West District}

From the table below, poor internet connectivity was strongly agreed as a barrier to the adoption of telemedicine by $37.0 \%$ and agreed by $39.0 \%$ of the respondent. More than $70 \%$ of respondents regarded the high cost of data as a barrier to the usage of telemedicine. In contrast, $69.5 \%$ of respondents agreed or strongly agreed that ambiguity in messages is also a barrier. Less than $60 \%$ of respondents see a lack of personal feeling they enjoy at the presences of the health workers as a hindrance to the adoption of telemedicine.

Telemedicine communications lack deeper understanding according to more than $60 \%$ of respondents as they see this as barriers to adoption. Finally, inconsistencies in automated messages were also identified as a blockage to telemedicine usage.

Table 4. Barriers to Adoption of Telemedicine in the Ga West District: $\mathrm{N}=226$

\begin{tabular}{lll}
\hline Barriers & Frequency & Percentage (\%) \\
\hline Poor internet connectivity & 14 & 6.2 \\
Disagree & 16 & 7.1 \\
Moderately Disagree & 25 & 11.1 \\
Neither Disagree or Agree & 88 & 39.0 \\
Agree & 83 & 37.0 \\
Strongly Agree. & & \\
\hline Lack of data or high cost of data & 16 & 7.1 \\
Disagree & 15 & 7.0 \\
Moderately Disagree & 26 & 12.5 \\
Neither Disagree or Agree & 88 & 39.0 \\
Agree & 81 & 34.1 \\
Strongly Agree. & & \\
\hline Ambiguity in messages they received & 18 & 7.9 \\
Disagree & 21 & 8.1 \\
Moderately Disagree & 29 & 13.2 \\
Neither Disagree or Agree & 82 & 36.3 \\
Agree & 75 & 33.2 \\
Strongly Agree. & & \\
\hline Difficulty getting deeper understanding from health workers & 22 & 9.7 \\
Disagree & 18 & 8.1 \\
Moderately Disagree & 29 & 13.3 \\
Neither Disagree or Agree & 82 & 36.3 \\
Agree & 71 & 31.4 \\
Strongly Agree. & & \\
\hline Lack of the feeling of personal presence & 27 & 12.0 \\
Disagree & 27 & 12.0 \\
Moderately Disagree & 34 & 15.0 \\
Neither Disagree or Agree & 72 & 32.1 \\
Agree & 65 & 28.8 \\
Strongly Agree. & & \\
\hline & & \\
\hline
\end{tabular}


Lack of pictorial presentation and actions exhibited at the hospital

Disagree

Moderately Disagree

10.2

Neither Disagree or Agree

Agree

Strongly Agree.

Automated messages are inconsistent with patients conditions

Disagree

$17 \quad 7.5$

Moderately Disagree

$15 \quad 6.6$

Neither Disagree or Agree

$25 \quad 11.1$

Agree

87

38.1

Strongly Agree.

5.5 Association between Educational Level of Respondents and Barriers to Adoption of Telemedicine

From the table below, education has a negative association with ambiguity in messages received by patients $(r=-.761)$, therefore the higher the education level of the respondents the lesser telemedicine communication appeared to be ambiguous.

Table 5. Association between educational level of respondents and barriers to adoption of telemedicine using pairwise correlation

$\begin{array}{lllll}1 & 2 & 3 & 4 & 5\end{array}$

\begin{tabular}{|c|c|c|c|c|c|}
\hline Education (1) & 1.00 & & & & \\
\hline $\begin{array}{l}\text { Ambiguity in messages } \\
\text { (2) }\end{array}$ & $-.761(.000) * * *$ & 1.00 & & & \\
\hline $\begin{array}{l}\text { Difficulty in the } \\
\text { understanding of } \\
\text { messages (3) }\end{array}$ & $-.755(00) * *$ & $.632(.00)^{* *}$ & 1.00 & & \\
\hline $\begin{array}{l}\text { In consistent in } \\
\text { automated messages (4) }\end{array}$ & $.443(.423)$ & $0.452(.341)$ & $.334(.452)$ & 1.00 & \\
\hline $\begin{array}{l}\text { Lack of personal feeling } \\
\text { (5) }\end{array}$ & $.652(.00)^{* * *}$ & $0.341(.213)$ & $.451(.344)$ & $.762(.00)^{* *}$ & 1.00 \\
\hline $\begin{array}{l}\text { Poor internet } \\
\text { connectivity (6) }\end{array}$ & $.723(.000)^{* * *}$ & $.234(.456)$ & $.433(.652)$ & $.334(.351)$ & $.543(.712) \quad 1.00$ \\
\hline
\end{tabular}

Again, the higher education of the respondent, the clearer the telemedicine messages received by the respondent $(r=-.755)$. Inconsistency of automated messages appeared to have no association with the education levels of respondents. The issues of inconsistency in automated 


\section{Macrothink}

International Journal of Management Innovation Systems

ISSN 1943-1384

messages seemed to be a major barrier to the adoption of telemedicine in the Ga West District. Lack of personal feeling when receiving treatment through telemedicine is positively correlated with education $(\mathrm{r}=.652)$. This is an indication that, no matter the education level of the respondent, the feeling that void of personal feelings exists when receiving treatment through telemedicine.

\subsection{Influence of Selected Variables on Respondents Adaption of Telemedicine}

Logistic regression was run on the adoption of telemedicine on the following predictors; communication with health workers, call at will, cost of treatment, time at the hospital, traveling time, overcrowding at the hospital, infection at the hospital, treatment on phone, health worker phone engagement and chronic illness. The regression result, based on both T-values and p-value shows a statistically significant relationship between adaption to telemedicine and call at will, time at the hospital, infection at the hospital and chronic illness.

The odds ratio for the call at will shows that for a unit increase in call at will, the odds in favor of adaption to telemedicine increases by 1.349. The odds ratio of 1.502 for the time at the hospital means that for a unit increase in time at the hospital; the odds in favor of adaption to telemedicine increase by $150.2 \%$. For infection at the hospital and chronic illness, the odds ratio figure 4.590 and 1.048 shows that the odd in favor of adaption to telemedicine increase by 4.59 and 1.048 respectively.

Table 6. Logistic regression

\begin{tabular}{|c|c|c|c|c|c|c|c|}
\hline $\begin{array}{l}\text { Acceptance of } \\
\text { Telemedicine }\end{array}$ & $\begin{array}{l}\text { Odds } \\
\text { Ratio }\end{array}$ & St.Err. & T-Value & P-Value & \multicolumn{2}{|c|}{$\begin{array}{c}\text { [95\% Conf } \\
\text { Interval] }\end{array}$} & $\overline{\text { Sig }}$ \\
\hline $\begin{array}{l}\text { Communication with health } \\
\text { worker }\end{array}$ & 1.254 & .449 & 0.63 & .527 & .621 & 2.531 & \\
\hline Call at will & 1.349 & .53 & 2.76 & .044 & .625 & 2.913 & $*$ \\
\hline Cost of treatment & .538 & .334 & -1.00 & .319 & .159 & 1.818 & \\
\hline Time at the hospital & .502 & .442 & 2.78 & .043 & .089 & 2.819 & * \\
\hline Traveling Time & 1.05 & .741 & 3.07 & .945 & .263 & 4.19 & \\
\hline Overcrowding at hospital & .756 & .525 & -0.40 & .688 & .194 & 2.948 & \\
\hline Infection at Hospital & 4.59 & 3.786 & 1.85 & .065 & .911 & 23.12 & $*$ \\
\hline Treatment on phone & .391 & .338 & -1.09 & .277 & .072 & 2.124 & \\
\hline $\begin{array}{l}\text { Health worker phone } \\
\text { engagement }\end{array}$ & .936 & .64 & -0.10 & .093 & .245 & 3.571 & \\
\hline Chronic illness & 1.048 & .555 & 2.09 & .93 & .037 & 2.959 & $*$ \\
\hline Constant & 9.119 & 23.284 & 0.87 & .387 & .061 & 1359.674 & \\
\hline Mean Dependent Var & & 0.57 & SD Depe & ndent Var & & & 0.498 \\
\hline Pseudo R-Squared & & 0.18 & Number & Of Obs & & & 2.000 \\
\hline Chi-Square & & 29.9 & Prob $>C$ & & & & .0098 \\
\hline Akaike Crit. (AIC) & & 124.22 & Bayesiar & Crit. (BIC) & & & 0.697 \\
\hline
\end{tabular}

Note. $* * * \mathrm{P}<.01, * * \mathrm{P}<.05, * \mathrm{P}<.1$. 


\section{Discussion}

Adoption of telemedicine in developing countries seemed not to be smooth like how quick persons living in developed countries responded to the technology (Barney et al. 2020). The enabling environment for the successful adoption of the treatment process falls short of what can support telemedicine operations (Loeb et al., 2020).

The background variables of the respondents indicate the existence of a supportive environment for telemedicine activities. A high percentage of respondents were below the age of 50 years and can use the necessary technologies that are needed for the operation of telemedicine. Only less than $10 \%$ of the respondents have no forms of formal education, indicating that the rest over $90 \%$ of the respondent can read text messages and other modes of telemedicine communications (Mouchtouris et al., 2020).

Access to a mobile phone, useful gadget in telemedicine was high among the respondent and but they recognized the challenges of poor internet services which is likely to have negative effects on the adoption of telemedicine. Research shows that the success of telemedicine in developed countries was driven by the availability of internet connectivity (Kapoor et al., 2020).

\subsection{Awareness about Telemedicine in the Ga West District}

Telemedicine can only be experienced by patients or someone aiding patients to seek treatment (Negrini et al. 2020). More than 70\% of respondents have sought treatment or helped some in seeking treatment in the past three years; this provided them with the opportunity to be aware of telemedicine as a mode of seeking care. Though not all phone communication between healthcare workers and patients or caregivers can be regarded as telemedicine treatment (Aljaeed, Altuwaijiri, \& Albohairy 2019), such engagement paves the way for the smooth takeoff of telemedicine (Rao et al., 2020). The majority of respondents agreed of having telephone engagement with healthcare workers. Information about telemedicine appeared to be available to the respondents with more than $80 \%$ claiming to have heard the term telemedicine through either traditional media, social media, friends or family, clear indication that the term may not be new to the population (Barney et al., 2020).

Awareness about telemedicine among the respondents appears to very high as more than half of the emphatically stated mobile phone is a vital facility need for telemedicine operations, with voice calls being the most preferred method, findings of studies indicated that telephone calls or messaging were the most used telemedicine tools (Rao et al., 2020).

\subsection{Factors Influencing Adoption of Telemedicine in the Ga West District}

For health intervention to be successfully adopted, there is the need to examine the factors that will influence a person to accept the intervention (X. Wang et al., 2019). A key component of telemedicine is the ability of the patient to deal with the healthcare worker without traveling to the hospital always (Kapoor et al., 2020). The majority of respondents see not traveling to hospitals as an attraction to the use of telemedicine since they will not need to do regular visitation to the hospital. Healthcare facilities in developing countries are very few, as it not 
proportion to the population size, coupled with fewer health professionals to staff these facilities (Barney et al., 2020), patients have to waste time to receive treatment for cases which are sometimes marginal (Saleem et al., 2020). Respondents agreed that telemedicine has the antidote to overcrowding in hospitals.

Regular visitation to the hospitals, especially in cases of persons with chronic conditions comes with a lot of traveling costs (Negrini et al., 2020). With telemedicine, the patient can receive directives from healthcare professionals even at their homes (Iyengar, Jain, \& Vaishya, 2020). Respondent agreed that a reduction in the cost of treatment through telemedicine is enough to influence them to adopt the practice. Fewer health facilities and fewer health professionals in developing countries, hospitals are mostly overcrowded, making patients contract infections from the hospital environment (Mbarika, 2002). Since telemedicine is not carried out in the hospital, the risk of such infections are far gone, respondents laid claim to this as a factor prompting the adoption of telemedicine. Telemedicine provides flexibility in patient and healthcare professional interaction; patients can call on health professionals at specific times or at will (Conde-blanco et al., 2020). The majority of the respondents recognized this as a factor that persuades their adoption of telemedicine.

\subsection{Barriers to Adoption of Telemedicine in the Ga West District}

For the successful adoption of health telemedicine, there is a need to identify barriers and draw strategies to surmount such barriers (Iyengar, Jain, \& Vaishya 2020). The adoption of telemedicine in Africa has faced many challenges ranging from the ability of citizens to use the technology, availability of internet connectivity and others (Mbarika, 2002). More than half of the respondents agreed with the statement that internet connectivity is a barrier. In Ghana, likewise, many sub-Sahara African countries, internet connectivity is accessible in the cities and charges for data usage are usually expensive (Roncero et al., 2020). Villages mostly lack internet connectivity, with some villages experiencing fluctuations in internet connectivity (Harling et al., 2020). Since telemedicine mostly drives on internet connectivity, communication flow between health professionals and patients is not smooth. This affects telemedicine operations leading to lost information and untimely delivery of instruction (Iacoella \& Tirivayi, 2019).

The high illiteracy level and cosmopolitan nature of communities affect the understanding of telemedicine messages from both health professionals and patients (Harling et al., 2020). Healthcare professionals and patients do not speak the same languages. Though English can be a common medium, illiteracy among citizens make communication very difficult and affects their understanding of information (Iacoella \& Tirivayi, 2019). The majority of the respondent acknowledged the fact that ambiguity in messages and lack of a more profound understanding of the message are barriers preventing the adoption of telemedicine Ga West Community.

Telemedicine messages come in the forms of voice messages, text messages, videos and others (Gutkin et al., 2020), in many cases these messages are sometimes automated and do match the receivers' condition (Roncero et al., 2020). Most of these messages are regarded as junk, and less attention is paid to them (Baudier, Kondrateva, \& Ammi, 2020). Telemedicine reduces that personal feeling one experience during personal interaction with a health professional 


\section{MInstitute Macrothink $^{\text {Int }}$}

International Journal of Management Innovation Systems

ISSN 1943-1384

2021, Vol. 6, No. 1

(Roncero et al., 2020). It also reduces the experiences of body examination. These made people look unfavorably at the efficacy of telemedicine (Wang et al., 2019). These are all barriers impeding the adoption of telemedicine in the community, according to the respondents.

\section{Conclusion}

The current upsurge in technological development is an indication that telemedicine holds the future of medical services, as such every nation must work hard to improve the enabling environment for successful adoption of this medical breakthrough. Developing nations must take a key interest in telemedicine since it can help to feel the most of the gaps that are existing in their health delivery.

\section{Recommendation}

The study has revealed some challenges that are impeding the adoption of telemedicine in the Ga West District and the following recommendation can help pave the way for the smooth adoption of the technological breakthrough. Internet connectivity must be improved with a reduction in the cost of data to enable public access information with ease. There must be a comprehensive education of the public about telemedicine and its advantages. Healthcare professionals can also introduce telemedicine to clients at any time they visit hospitals.

\section{References}

Aljaeed, R., Sarah, A., \& Tahani, A. (2019). Telemedicine in Riyadh Region, Saudi Arabia. Journal of Infection and Public Health, 1-7. https://doi.org/10.1016/j.jiph.2019.04.006

Appiah, F. et al. (2020). Trends and Determinants of Contraceptive Use among Female Adolescents in Ghana: Analysis of 2003-2014 Demographic and Health Surveys. SSM Population Health, 10, 100554. https://doi.org/10.1016/j.ssmph.2020.100554.

Arendt, K. W. (2016). The 2016 Hughes Lecture What's New in Maternal Morbidity and Mortality?

Barney, A., Sara, B., Veronika, M., \& Raymond-flesch, M. (2020). The COVID-19 Pandemic and Rapid Implementation of Adolescent and Young Adult Telemedicine: Challenges and Opportunities for Innovation. Journal of Adolescent Health, 67(2), 164-71. https://doi.org/10.1016/j.jadohealth.2020.05.006

Baudier, P., Galina, K., \& Chantal, A. (2020). The Future of Telemedicine Cabin? The Case of the French Students'. Futures, 102595. https://doi.org/10.1016/j.futures.2020.102595

Blankson, P. K., Justice, N., Genevieve, A., \& Moses, A. (2020). Injuries and Their Related Household Costs in a Tertiary Hospital in Ghana. African Journal of Emergency Medicine, (July 2019), 1-6. https://doi.org/10.1016/j.afjem.2020.04.004

Conde-blanco, E. et al. (2020). Epilepsy \& Behavior Emergency Implementation of Telemedicine for Epilepsy in Spain: Results of a Survey during SARS-CoV-2 Pandemic. Epilepsy \& Behavior, 111, 107211. https://doi.org/10.1016/j.yebeh.2020.107211 


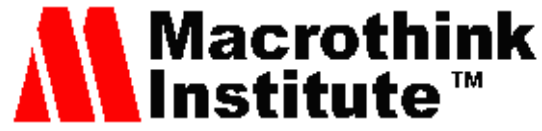

International Journal of Management Innovation Systems ISSN 1943-1384

Cunha, C. R. et al. (2018). ScienceDirect ScienceDirect Using Pervasive and Mobile Computation in the Provision of Using Pervasive and Mobile Care Computation the Provision of Gerontological in Rural in Areas Gerontological Care in Rural Areas. Procedia Computer Science, 138, 72-79. https://doi.org/10.1016/j.procs.2018.10.011

Fletcher, S. R. et al. (2020). Adaptive Automation Assembly: Identifying System Requirements for Technical Efficiency and Worker Satisfaction. Computers and Industrial Engineering, 139(March 2019), 105772. https://doi.org/10.1016/j.cie.2019.03.036

González-martín, S. et al. (2019). Intensive \& Critical Care Nursing Effects of a Visit Prior to Hospital Admission on Anxiety, Depression and Satisfaction of Patients in an Intensive Care Unit.

Gutkin, P. M. et al. (2020). Telemedicine in Radiation Oncology: Is It Here to Stay? Impacts on Patient Care and Resident Education. Radiation Oncology Biology, 108(2), 416-20. https://doi.org/10.1016/j.ijrobp.2020.06.047.

Gyapong, A. Y. (2020). How and Why Large Scale Agricultural Land Investments Do Not Create Long-Term Employment Benefits: A Critique of the 'State' of Labour Regulations in $\begin{array}{llll}\text { Ghana. Land } & \text { Use } & \text { Policy, } & \end{array}$ https://doi.org/10.1016/j.landusepol.2020.104651

Hamilton, E. et al. (2019). Clinical and Translational Radiation Oncology Telehealth in Radiation Oncology at the Townsville Cancer Centre: Service Evaluation and Patient Satisfaction. Clinical and Translational Radiation Oncology, 15, 20-25. https://doi.org/10.1016/j.ctro.2018.11.005

Han, E. et al. (2019). The Role of Community-Based Nursing Interventions in Improving Outcomes for Individuals with Cardiovascular Disease: A Systematic Review. International Journal of Nursing Studies, 103415. https://doi.org/10.1016/j.ijnurstu.2019.103415.

Harling, G. et al. (2020). Social Science \& Medicine Social Contact, Social Support, and Cognitive Health in a Population-Based Study of Middle-Aged and Older Men and Women in Rural South Africa. Social Science \& Medicine, 260(April), 113167. https://doi.org/10.1016/j.socscimed.2020.113167.

Iacoella, F., \& Tirivayi, N. (2019). Determinants of Maternal Healthcare Utilization among Married Adolescents: Evidence from 13 Sub-Saharan African Countries.

Iyengar, K., Vijay, K. J., \& Raju, V. (2020). Diabetes \& Metabolic Syndrome: Clinical Research \& Reviews Pitfalls in Telemedicine Consultations in the Era of COVID 19 and How to Avoid Them. Diabetes \& Metabolic Syndrome: Clinical Research \& Reviews, 14(5), 797-99. https://doi.org/10.1016/j.dsx.2020.06.007

Kapoor, S.et al. (2020). Developing a Pediatric Ophthalmology Telemedicine Program in the COVID-19 Crisis. Journal of AAPOS. https://doi.org/10.1016/j.jaapos.2020.05.008

Khosla, S. (2020). Implementation of Synch Ronous Telemedicine into Clinical Practice. Clinics in Sleep Medicine, 15(3), 347-58. https://doi.org/10.1016/j.jsmc.2020.05.002. 


\section{MInstitute ${ }_{\text {Mnk }}^{\text {Macrothin }}$}

International Journal of Management Innovation Systems

ISSN 1943-1384

Loeb, S. et al. (2020). Telemedicine and Smart Working: Recommendations of the European Association of Urology.

Mbarika, V. W. A. (2002). Telemedicine in Sub-Saharan Africa: A Proposed Delphi Study.

Mouchtouris, N. et al. (2020). Telemedicine in Neurosurgery: Lessons Learned and Transformation of Care During the COVID-19 Pandemic. World Neurosurgery, 140, e387-94. https://doi.org/10.1016/j.wneu.2020.05.251.

Negrini, S. et al. (2020). Feasibility and Acceptability of Telemedicine to Substitute Outpatient Rehabilitation Services in the COVID-19 Emergency in Italy: An Observational Everyday Clinical-Life Study. Archives of Physical Medicine and Rehabilitation, 1-6. https://doi.org/10.1016/j.apmr.2020.08.001

Rao, S. S. et al. (2020). Arthroplasty Today Establishing Telemedicine in an Academic Total Joint Arthroplasty Practice: Needs and Opportunities Highlighted by the COVID-19 Pandemic. Arthroplasty Today, 6(3), 617-22. http://dx.doi.org/10.1016/j.artd.2020.04.014.

Roncero, C. et al. (2020). The Response of the Mental Health Network of the Salamanca Area to the COVID-19 Pandemic: The Role of the Telemedicine. Psychiatry Research, 291(June), 113252. https://doi.org/10.1016/j.psychres.2020.113252

Saleem, S. M., Louis, R. P., Paul, A. S., \& James, C. T. (2020). Virtual Ophthalmology: Telemedicine in A. American Journal of Ophthalmology, 216, 237-42. https://doi.org/10.1016/j.ajo.2020.04.029

Strohl, M. P. et al. (2020). ARTICLE IN PRESS Implementation of Telemedicine in a Laryngology Practice During the COVID-19 Pandemic: Lessons Learned, Experiences Shared.

Xiaoli, W., Zhiyong, Z., Jun, Z., \& Yongqiang, S. (2019). Impact of Telemedicine on Healthcare Service System Considering Patients ' Choice.

Yao-chin, W., Bilegjin, G., Chieh-chen, W., \& Usman, I. (2018). Computer Methods and Programs in Biomedicine Patient Satisfaction with Dermatology Teleconsultation by Using MedX. Computer Methods and Programs in Biomedicine, 167, 37-42. https://doi.org/10.1016/j.cmpb.2018.10.015

\section{Copyright Disclaimer}

Copyright for this article is retained by the author(s), with first publication rights granted to the journal.

This is an open-access article distributed under the terms and conditions of the Creative Commons Attribution license (http://creativecommons.org/licenses/by/3.0/). 